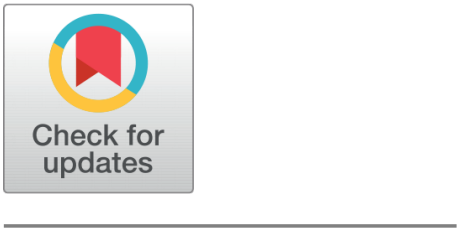

G OPEN ACCESS

Received: 26-04-2020

Accepted: 19-05-2020

Published: 17-06-2020

Editor: Dr. Natarajan Gajendran

Citation: Gogoi K, Deka M, Das J, Goswami AD (2020) A study of risk factors associated with essential Hypertension in an urban population of North East India. Indian Journal of Science and Technology 13(18): 1840-1847. https ://doi.org/10.17485/IJST/v13i18.410

*Corresponding author. Krishna Gogoi

Research Scholar, Department of Bioengineering \& Technology, Gauhati University, Guwahati, 781014, India. Tel.: +91-9864015831 krishna.rsguist@gmail.com

Funding: None

Competing Interests: None

Copyright: @ 2020 Gogoi, Deka, Das, Goswami. This is an open access article distributed under the terms of the Creative Commons Attribution License, which permits unrestricted use, distribution, and reproduction in any medium, provided the original author and source are credited.

Published By Indian Society for Education and Environment (iSee)

\section{A study of risk factors associated with essential Hypertension in an urban population of North East India}

\author{
Krishna Gogoi ${ }^{1}$, Manab Deka², Jharna Das ${ }^{1}$, Amal Dev Goswami ${ }^{3}$ \\ 1 Research Scholar, Department of Bioengineering \& Technology, Gauhati University, \\ Guwahati, 781014, India. Tel.: +91-9864015831 \\ 2 Professor and Director GUIST, Gauhati University, Guwahati, 781014, India \\ 3 Physician, Department of Medicine, NEMCARE Hospital, Guwahati, 781005, India
}

\section{Abstract}

Objectives: To assess the impact of sociodemographic factors, lifestyle habits and lipid profile, associated with development of Essential Hypertension in an urban population of North-Eastern region of India. Materials \& Methods: Hypertension was defined as per Clinical Practice guidelines 2017. A total number of 400 subjects -200 normotensive and 200 hypertensives were enrolled in this case-control study. The subjects underwent Blood Pressure measurement, anthropometric measurements and Electrocardiography. Detailed sociodemographic data, medical history and personal history were noted. Serum lipid profile was estimated for all the subjects. Statistical analysis was performed in SPSSvs16. Findings: Among the 200 Normotensives 69 (17.2\%) had elevated BP. In the Essential Hypertensive group 24 (6\%) were Stage 1 and 176 (44\%) were stage 2 hypertensives. A statistically significant number of $88 \%$ (176) hypertensive subjects were above 40 years of age ( $p$ value $<0.001$ ). Among the socio-demographic factors high risk of hypertension was associated with gender male [OR 1.59 (1.064, 2.402)], Body Mass Index $\geq 25$ [OR 2.98(1.986, 4.497)], sedentary work activity [OR $8.3(5.124,13.48)]$, extra salt intake [OR 1.99 $(1.165,2.584)]$, alcohol [OR $1.99(1.084,3.683)]$ and tobacco users [OR 2.1(1.374, 3.187)]. The serum lipids Cholesterol $\geq 200 \mathrm{mg} / \mathrm{dl}$, triglycerides $\geq 150 \mathrm{mg} / \mathrm{dl}$, Low Density Lipoproteins $\geq 100 \mathrm{mg} / \mathrm{dl}$ and cholesterol: High Density Lipoprotein ratio $>3$ was significantly associated with hypertension. Conclusion: The present study highlights the association of age, high BMl, sedentary habits, consumption of extra salt, alcohol, tobacco use and dyslipidemia as major risk factors associated with Essential Hypertensive subjects in urban adults in Assam. Novelty: The study highlights the different predictors of Essential Hypertension in North Eastern Indian urban adults.

Keywords: Essential hypertension; Blood pressure; Overweight; Extra salt intake; Serum lipids; Sedentary activity 


\section{Introduction}

Hypertension or high blood pressure (BP) is a global health problem. Nearly 1.13 billion people worldwide have hypertension and most people with high blood pressure are not aware that they have hypertension. ${ }^{(1)}$

Hypertension without any underlying cause it is labeled as Essential Hypertension (EH). Approximately $5 \%$ of patients with hypertension have underlying renal, cardiac, arterial or endocrine disorder are classified as Secondary Hypertension ${ }^{(2)}$.

Uncontrolled EH leads to increased morbidity and mortality. It increases the risk of cardiovascular complications and other organ diseases. Nearly $44 \%$ of premature deaths caused annually by major Non-Communicable diseases worldwide were attributed to cardiovascular diseases ${ }^{(3)}$. Hypertension and dyslipidemia are major modifiable risk factors for cardiovascular disease $(\mathrm{CVD})^{(4,5)}$.

More recently it has been reported that hypertension was a common co-morbid condition associated with the ongoing COVID-19 pandemic caused by severe acute respiratory corona virus -2 SARS-CoV-2 by several Chinese researchers ${ }^{(6,7)}$. Considering the fact that majority of the COVID-19 patients with critical illness were elderly and hypertension is more frequently encountered in this age group, these findings may not reflect a causal role of hypertension in COVID-19 infection and severity. The virus gains entry into cells by binding to the Angiotensin converting enzyme (ACE) 2 in the lungs. However, it is still not clear whether the antihypertensive drugs ACE inhibitors and angiotensin -II type 1 receptor blockers are beneficial or detrimental in COVID-19 infections ${ }^{(8,9)}$.

The prevalence of hypertension across the World Health Organization (WHO) region was highest in Africa at $46 \%$ and lowest in America at 35\% for both sexes ${ }^{(10)}$. In India the prevalence of the disease varies from $9.3 \%$ to $47.9 \%$ in different sets of population of the country ${ }^{(11-15)}$. The prevalence of elevated BP in urban dwellers varied between $11.5 \%-31.5 \%$ and that in rural population from $10.6 \%-33.8 \%^{(12-14)}$.

In the state of Assam the prevalence of hypertension was reported to be $15 \%-25 \%$ across the different districts in 2015 $2016^{(13)}$. In Assamese rural population the prevalence was reported to be $33.3 \%{ }^{(16)}$. High BP was more frequent in Indians at a younger age than western countries ${ }^{(17)}$.

With rapid urbanization, movement of people from rural to urban area, changes in eating habits and unhealthy lifestyle has led to the emergence of hypertension as a major global disease. Association of various risk factors with hypertension like overweight, smoking tobacco, alcohol intake, psychosocial stress and lack of physical exercise among others have been explored by many researchers with varying results. The association between dyslipidemia and hypertension also varies significantly from region to region in different population ${ }^{(18-22)}$.

Situated in the state of Assam, Guwahati is a rapidly expanding city in North Eastern region of India. As such along with urbanization, the city populace is exposed to the risk factors of urban dwellers. The objective of the present case - control study was to (i) assess the sociodemographic and lifestyle characteristics and (ii) To assess the serum lipid profile in Essential hypertensive and Normotensive subjects residing in Guwahati City. The knowledge is relevant for the clinician and the patients for planning management strategies for the patient, including lifestyle modification, rationale for use of lipid lowering drugs and antihypertensive medication, thereby helping in prevention of CVD.

\section{Materials and Methods}

The present study was a case-control study carried out from April 2014 to March 2019. The study was approved by the Guwahati University Institutional Ethics Committee.

\subsection{Selection of patients}

A total number of 400 participants with and without EH between $18-65$ years who had been residing in Guwahati city for at least last 5 years were randomly selected for the study. Hypertension was defined as Systolic BP $\geq 130 \mathrm{~mm}$ of $\mathrm{Hg}$ or DBP $\geq 80$ $\mathrm{mm}$ of $\mathrm{Hg}$ as per published guidelines of American College of Cardiology (ACC)/American heart Association (AHA) $2017^{(23)}$. The participants were enrolled following measurement of office BP at the physician's office. All the subjects were consented to prior to enrolment.

\subsection{Inclusion and exclusion criteria}

Adult patients with newly detected hypertension and known cases of uncontrolled EH were included as cases. The control group composed of healthy volunteers. All the subjects had a normal baseline Electrocardiogram (ECG). Patients with secondary hypertension, hypertensive on lipid lowering drugs, children, pregnant women, individuals with cognitive disorders, cardiac disease, hormonal imbalance or diseases like chronic kidney disease, neurological disorders, etc. were excluded from this study. 


\subsection{BP and anthropometric measurement}

The $\mathrm{BP}$ recorded was the average of 2 readings taken 5-10 minutes apart after the subject had rested for 15 minutes. All the subjects underwent a general physical examination and anthropometric measurement. The Body mass Index (BMI) was calculated using the formula weight in kilogram / square of height in meter. Subjects with BMI $\geq 25$ were considered overweight.

\subsection{Data collection}

All data were collected using a pre-defined questionnaire. Information was collected on occupational status, socioeconomic status (SES), personal history - use of extra salt ( $>5 \mathrm{~g} /$ day), history of tobacco use - smoking and smokeless, alcohol consumption and physical activity. Ways of extra salt intakes was noted as over the table, fast food, processed food or any other form. The subjects who were current and past alcoholics who had consumed alcohol/used any form of tobacco within last one year were considered alcohol and tobacco users.

\subsection{Biochemical analysis}

For serum lipids estimation $4 \mathrm{ml}$ of venous blood was collected from the participants in fasting state (overnight). Serum lipids estimated were - cholesterol (CHOL) and Triglyceride (TGL) were estimated by enzymatic colorimetric methods; high density lipoprotein cholesterol (HDLC) by direct selective inhibition method and low-density lipoprotein cholesterol (LDLC) by direct solubilisation method. The cholesterol: HDLC ratio was calculated. Prevalence of dyslipidemia was assessed as per National Cholesterol Education Program Expert Panel - Adult treatment Panel III (NCEP ATP iii) ${ }^{(4)}$.

\subsection{Statistical analysis}

The data were analysed using standard statistical methods using Statistical package for social sciences software (SPSS vs16) whenever required. For continuous variables data were presented in mean \pm standard deviation and compared using independentsamples t-test. The educational status, occupation, SES and physical activity were presented in numbers and percentage. Chi square test was used to compare the distribution of categorical risk factors. The measure of association between risk factors including lipid profile and hypertension was expressed in odds ratio (95\% Confidence Interval). A binary logistic regression was performed to assess the interaction between age, sex, BMI and serum lipids with hypertension. The statistical results were considered significant at two-tailed $\mathrm{p}$ value $<0.05$.

\section{Results}

Out of total 400 subjects, majority of subjects were males (62\%), $45.8 \%$ were overweight (BMI $\geq 25), 12.75 \%$ consumed alcohol, $34.8 \%$ were tobacco-users and $27.3 \%$ consumed extra salt.

Highest number (42.5\%) of subjects in the normotensive group was in the age group 36-45 years while maximum numbers (45.5\%) of hypertensives were in the age group 46-55 years and were males [ Table 1 ]. There was a significant difference in the mean age (in years) of controls (41.24 \pm 7.74$)$ and cases (46.09 \pm 6.46$) ; t=6.84(398), p<0.05$. A total number of $176(88 \%)$ hypertensive subjects and $114(55 \%)$ normotensive subjects were aged $\geq 40$ years. The risk of hypertension increased in the subjects aged $\geq 40$ years, with an OR $5.5(3.322,9.214)$ and $p$ value $<0.001$ (Data not shown).

The different categories of subjects in the present study as per ACA/AHA Clinical Practice Guidelines 2017 are shown in Table 2. A total number of 126 (31.6\%) subjects were unaware that they had elevated BP or EH. Of these $17.2 \%$ had normal but elevated BP and $14.3 \%$ had stage 1 or stage 2 HTN. The difference between mean SBP (in mm Hg) scores of controls (115 \pm 7.41 ) and cases $(153 \pm 12.8)$ and DBP (in $\mathrm{mmHg}$ ) of controls $(75.11 \pm 5.48)$ and cases $(89.96 \pm 9.42)$ was significant with $\mathrm{t}=36.18(398)$, $\mathrm{p}<0.05$ and $\mathrm{t}=18.95(398), \mathrm{p}<0.05$ respectively.

SES, educational status, occupational status and physical activity of hypertensive cases and normotensive controls are shown in [ Table 3 ]. Overall combined (37.8\%) and in both the groups - cases (37.5\%) and controls (38\%), majority of subjects were well educated (professional/post graduates/graduates). Maximum number of subjects belonged to upper middle class (64.5\%). Unemployment was more frequent in the group cases (39\%) compared to the control group (5\%). $77.5 \%$ of the hypertensive subjects were in the SES category of upper middle class. Sedentary physical activity was more common among the hypertensives (58.5\%) while $81.5 \%$ of the normotensives were moderately active. Type of physical activity had significant association with hypertension.

Association of risk factors with EH is presented in [ Table 4]. Males were significantly more at risk of developing hypertension than females - OR 1.59(1.064, 2.402), p value - 0.01. Other risk factors - (BMI $\geq 25)$, extra salt intake, alcohol consumption, 
Table 1. Age- and gender-wise distribution of subjects

\begin{tabular}{|c|c|c|c|c|}
\hline Age (in years) & Gender & $\begin{array}{l}\text { Normotensive } \\
(\mathrm{n}=200)\end{array}$ & Hypertensive $(n=200)$ & $\begin{array}{l}\text { Total } \\
(\mathrm{N}=400)\end{array}$ \\
\hline \multirow{3}{*}{$<25$} & $\mathrm{M}$ & $0(0)$ & $0(0)$ & $0(0)$ \\
\hline & $\mathrm{F}$ & $3(1.5)$ & $1(0.5)$ & $4(1)$ \\
\hline & Total & $3(1.5)$ & $1(0.5)$ & $4(1)$ \\
\hline \multirow{3}{*}{$26-35$} & $\mathrm{M}$ & $29(14.5)$ & $6(3.0)$ & $35(8.75$ \\
\hline & $\mathrm{F}$ & $23(11.5)$ & $5(2.5)$ & $28(7.0)$ \\
\hline & Total & $52(26)$ & $11(5.5)$ & $63(15.7)$ \\
\hline \multirow{3}{*}{$36-45$} & M & $53(26.5)$ & $54(27)$ & $107(26.8)$ \\
\hline & $\mathrm{F}$ & $32(16)$ & $33(16.5)$ & $65(16.2)$ \\
\hline & Total & $85(42.5)$ & $87(43.5)$ & $172(43.0)$ \\
\hline \multirow{3}{*}{$46-55$} & M & $27(13.5)$ & $68(34)$ & $95(23.8)$ \\
\hline & $\mathrm{F}$ & $27(13.5)$ & $23(11.5)$ & $50(12.5)$ \\
\hline & Total & $54(27)$ & $91(45.5)$ & $145(36.3)$ \\
\hline \multirow{3}{*}{$56-65$} & M & $4(2.0)$ & $7(3.5)$ & $11(2.8)$ \\
\hline & $\mathrm{F}$ & $2(1.0)$ & $3(1.5)$ & $5(1.2)$ \\
\hline & Total & $6(3)$ & $10(5.0)$ & $16(4.0)$ \\
\hline
\end{tabular}

M: Male; F: Female; Data are number (percentage)

Table 2. Categorization of subjects as per ACA/AHA Clinical Practice Guidelines 2017

\begin{tabular}{llll}
\hline CategoryBP $($ in $\mathbf{~ m m H g})$ & Male $(\mathbf{n}=\mathbf{2 4 8})$ & Female $(\mathbf{n}=\mathbf{1 5 2})$ & Total $(\mathbf{n = 4 0 0 )}$ \\
\hline Normotensive & & & \\
Normal $(\mathrm{SBP}<120$ and DBP $<80)$ & $71(28.6 \%)$ & $60(39.5 \%)$ & $131(32.8 \%)$ \\
Elevated(SBP 120-129 and DBP $<80)$ & $42(16.9 \%)$ & $27(17.8 \%)$ & $69(17.2 \%)$ \\
\hline Hypertensive & & & $24(6 \%)$ \\
Stage 1 ( SBP 130-139 or DBP 80-89) & $18(7.3 \%)$ & $6(3.9 \%)$ & $176(44 \%)$ \\
Stage 2( SBP $\geq 140$ or DBP $\geq 90)$ & $117(47.2 \%)$ & $59(38.8 \%)$ & \\
\hline
\end{tabular}

SBP: Systolic blood pressure; DBP: diastolic blood pressure

tobacco use and sedentary work activity were significantly associated with increased risk of EH (p value $<0.05$ ). The tobacco use was in the form of zarda, khaini, ghutka, smoke and tobacco leaf with raw betel nut and betel leaf. Of the serum lipids, except low HDLC ( $<40 \mathrm{mg} / \mathrm{dl}$ in males and $<50 \mathrm{mg} / \mathrm{dl}$ in females) all the other parameters were significantly associated with hypertension.

Logistic regression was performed to obtain a best fit model for variables age, gender, BMI and lipid profile on the likelihood that participants have HTN. The model was statistically significant with chi square $178.675, \mathrm{df}=8, \mathrm{p}<0.05 .81 .5 \%$, outcomes CONTROL of variable DISEASE and 76.5\% outcomes CASES were predicted correctly. Males were 1.78 times more likely to have hypertension than females. Increasing age, BMI \& serum triglycerides was associated with an increased likelihood of suffering from HTN [ Table 5].

\section{Discussion}

In the present study, investigation was conducted on the relationships between socio-demographic characteristics, lifestyle habits and serum lipid profile with EH, in an urban population of Assam. The results revealed hypertension was more frequent in males. This was similar to the findings of other Indian studies ${ }^{(12,14,15,18,20)}$. An earlier report from Pudducherry did not report any association between gender and $\mathrm{HTN}^{(24)}$. The risk of developing hypertension increased in subjects who consumed extra salt, consumed alcohol, tobacco users and sedentary workers which was according to other reports ${ }^{(16,18,24,25)}$.

There has been a change in the categorisation of blood pressure from The Seventh Report of the Joint National Committee on Prevention, Detection, Evaluation, and Treatment of High Blood Pressure (JNC7) to the recent guidelines followed by ACA/AHA ${ }^{(26)}$. Most of the earlier reports were based on the JNC6 or JN7 classification ${ }^{(12-16,18,20,24)}$. In the recent guidelines 
Table 3. Education, occupation, SES and physical activity of the subjects

\begin{tabular}{|c|c|c|c|}
\hline Parameter & $\begin{array}{l}\text { Normotensive } \\
(\mathrm{n}=200)\end{array}$ & $\begin{array}{l}\text { Hypertensive } \\
(\mathrm{n}=200)\end{array}$ & $\begin{array}{l}\text { Total } \\
(\mathrm{N}=400)\end{array}$ \\
\hline \multicolumn{4}{|l|}{ Education } \\
\hline Professional & $5(2.5)$ & $4(2)$ & $9(2.25)$ \\
\hline Post graduate/Graduate & $71(35.5)$ & $71(35.5)$ & $142(35.5)$ \\
\hline Higher secondary & $61(30.5)$ & $41(20.5)$ & $102(25.5)$ \\
\hline High school & $30(15)$ & $44(22)$ & $74(18.5)$ \\
\hline Middle school & $06(3)$ & $21(10.5)$ & $27(6.75)$ \\
\hline Literate & $26(13)$ & $14(7)$ & $40(10)$ \\
\hline Illiterate & $01(0.5)$ & $5(2.5)$ & $6(1.5)$ \\
\hline \multicolumn{4}{|l|}{ Occupation } \\
\hline Professional & $10(5)$ & $6(3)$ & $16(4)$ \\
\hline Associate professional & $59(29.5)$ & $49(24.5)$ & $108(27)$ \\
\hline Clerk/Shop/Farmer & $59(29.5)$ & $27(13.5)$ & $86(21.5)$ \\
\hline Skilled worker & $23(11.5)$ & $27(13.5)$ & $50(12.5)$ \\
\hline Semi-skilled worker & $02(1)$ & $7(3.5)$ & $9(2.25)$ \\
\hline Unskilled worker & $37(18.5)$ & $6(3)$ & $43(10.8)$ \\
\hline Unemployed & $10(5)$ & $78(39)$ & $88(2.2)$ \\
\hline \multicolumn{4}{|l|}{ SES } \\
\hline Upper & $13(6.5)$ & $08(4)$ & $21(5.3)$ \\
\hline Upper middle & $103(51.5)$ & $155(77.5)$ & $258(64.5)$ \\
\hline Lower middle & $76(38)$ & $32(16)$ & $108(27)$ \\
\hline Lower & $08(4)$ & $5(2.5)$ & $13(3.2)$ \\
\hline \multicolumn{4}{|l|}{ Physical activity } \\
\hline Sedentary & $29(14.5)$ & $117(58.5)$ & $146(36.5)$ \\
\hline Moderate & $163(81.5)$ & $74(37)$ & $237(59.3)$ \\
\hline Vigorous & $8(4)$ & $9(4.5)$ & $17(4.2)$ \\
\hline
\end{tabular}

Data are number(percentage)

the SBP and diastolic BP has been fixed in the normal and elevated BP group to $<120 \mathrm{mmHg}$ and $<80 \mathrm{~mm} \mathrm{Hg}$ respectively. The Pre-hypertension group (SBP 120-139 mmHg or DBP 80-89 mm Hg) in JNC7 with DBP $>80 \mathrm{~mm} \mathrm{Hg}$ is now labelled as Stage 1 HTN. The subjects with elevated blood pressure are more at risk of developing CVD and progressing to hypertension ${ }^{(23)}$.

The finding in the present study that $31.6 \%$ subjects were unaware of their elevated BP or hypertension status is a matter of serious public health concern as it is a major risk factor for cardiac disease like heart attacks, atrial fibrillation, renal damage and cognitive impairment ${ }^{(1,17)}$. Unawareness of BP status in the population was an important finding in other Indian studies and varied from $20.8 \%$ to more than $50 \%$ of hypertensive cases ${ }^{(12,14)}$.

In the present study age above 40 years was a significant risk factor (OR: 5.5). Other studies from across the country have reported significant correlation of hypertension with increasing age ${ }^{(12,15,16,18,24)}$.

Obesity is a major risk factor in the development of hypertension and CVD ${ }^{(16,18,21,27)}$. Our study showed significant association of overweight with hypertension. Subjects with BMI values $\geq 25$ were more than 1.5 times at risk of developing hypertension. Blood pressure can be lowered by keeping the daily salt intake to less than $5 \mathrm{~g} /$ day, roughly equivalent to 1 teaspoon ${ }^{(28)}$. Extra salt was consumed in the form of processed food, fast food, over the table and snacking. It is a fairly common practice amongst Assamese people to consume green chillies and lemon slices with one or two extra pinches of salt. Earlier researchers have also reported similar results ${ }^{(14-16)}$. In our study risk of hypertension was higher (OR: 1.99) in extra-salt consumers.

Our study reported the educational level of majority of the subjects $(88.5 \%)$ was above literate. Being a literate has become a basic requirement to be eligible for many of the unskilled jobs. In contrast, earlier studies on Assamese population and aboriginal 
Table 4. Association of risk Factors with EH

\begin{tabular}{|c|c|c|c|c|}
\hline Parameter & Hypertensive $^{\star}(\mathrm{N}=200)$ & $\begin{array}{l}\text { Normotensive }^{*} \\
(\mathrm{~N}=200)\end{array}$ & OR $(95 \% \mathrm{CI})$ & Pvalue \\
\hline Gender-Male & $135(67.5)$ & $113(56.5)$ & $1.59(1.06-2.4)$ & 0.01 \\
\hline $\mathrm{BMI} \geq 25$ & $118(59)$ & $65(32.5)$ & $1.71(1.39-2.08)$ & $<0.001$ \\
\hline Tobacco User(yes) & $86(43)$ & $53(26.5)$ & $2.1(1.37-3.18)$ & $<0.001$ \\
\hline Alcohol(yes) & $33(16.5)$ & $18(9.0)$ & $1.99(1.08-3.68)$ & 0.01 \\
\hline Extra Salt (yes) & $125(62.5)$ & $95(47.5)$ & $1.99(1.165,2.584)$ & 0.003 \\
\hline Sedentary Work(yes) & $117(58.5)$ & $29(14.5)$ & $8.3(5.124,13.48)$ & $<0.001$ \\
\hline Cholesterol $\geq 200 \mathrm{mg} / \mathrm{dl}$ (yes) & $102(51)$ & $49(24.5)$ & $3.27(2.09-4.9)$ & $<0.001$ \\
\hline $\mathrm{TGL} \geq 150 \mathrm{mg} / \mathrm{dl}$ (yes) & $95(47.5)$ & $33(16.5)$ & $4.58(2.88-7.29)$ & $<0.001$ \\
\hline $\begin{array}{l}\text { HDLC } \\
<40 \mathrm{mg} / \mathrm{dl} \quad \text { (male) } \quad \text { (yes) }<50 \\
\mathrm{mg} / \mathrm{dl}(\text { female })(\text { yes })\end{array}$ & $63(31.5)$ & $74(37)$ & $0.78(0.52-1.18)$ & 0.12 \\
\hline LDLC $\geq 100 \mathrm{mg} / \mathrm{dl}$ (yes) & $158(79)$ & $134(67)$ & $1.85(1.18-2.91)$ & 0.003 \\
\hline Cholesterol/HDLC $>3$ (yes) & $188(94)$ & $175(87.5)$ & $2.23(1.09-4.59)$ & 0.01 \\
\hline
\end{tabular}

OR: odds ratio; CI: Confidence Interval; BMI: Body mass index; TGL: Triglycerides; HDLC: High density lipoprotein; LDLC: Low density lipoprotein; ${ }^{*}$ Column Data are number (percentage)

Table 5. Logistic regression model for association of hypertension and age, gender, BMI and serum lipids using cases and controls as dependent variable $(\mathrm{N}=400)$

\begin{tabular}{lllll}
\hline & B & Sig $^{*}$ & $\operatorname{Exp}(\mathbf{B})$ & 95\% CI \\
\hline Age & 0.110 & 0.000 & 1.117 & $1.077-1.157$ \\
Gender (Male) & 0.581 & 0.033 & 1.788 & $1.05-3.046$ \\
BMI & 0.217 & 0.0 & 1.242 & $1.148-1.343$ \\
Cholesterol & 0.016 & 0.239 & 1.016 & $0.989-1.044$ \\
HDLC & 0.015 & 0.556 & 0.985 & $0.938-1.035$ \\
TGL & 0.011 & .001 & 1.011 & $1.004-1.018$ \\
LDLC & 0.0 & 0.982 & 1.0 & $0.975-1.026$ \\
\hline
\end{tabular}

CI: Confidence interval; ${ }^{*}$ cut off $\mathrm{p}<0.05$

Nicobarese tribe, the number of well-educated subjects was the lowest ${ }^{(16,29)}$. Lack of adequate physical activity is associated with increased risk of non-communicable diseases ${ }^{(3)}$. We found that the subjects with sedentary lifestyle were at a very high risk of hypertension (OR: 8.3) similar to the findings in earlier studies ${ }^{(12,14-16,24)}$.

According to WHO report, tobacco use and alcohol consumption are major risk factors in causation of Non-Communicable disease epidemic worldwide ${ }^{(30)}$. Alcohol consumption (OR: 1.99) and tobacco use (OR: 2.0) was found to increase the risk of hypertension in the study. Smokeless tobacco was the commonest form of tobacco used. Tobacco smoking had no significant association with HTN and pre-hypertension in North Indian population study ${ }^{(15,18)}{ }^{\mathrm{t}} \mathrm{I}^{\mathrm{wa}}$ s reported in an earlier study that risk of hypertension was high among the exclusive smokeless tobacco users ${ }^{(31)}$. Significant association of alcohol consumption and hypertension was reported by earlier researchers ${ }^{(12,14,15,29)}$.

Dyslipidemia has a strong association with Hypertension and CVDs ${ }^{(32)}$. A study on affluent North Indian population reported significant association between TGL and HTN ${ }^{(16)}$. Other studies from Indore, Madhya Pradesh and Bangladesh reported significant difference in means of CHOL, TGL, LDLC and HDLC of normotensives and hypertensives ${ }^{(20,21)}$. In the present study the serum lipids cholesterol $\geq 200 \mathrm{mg} / \mathrm{dl}$, TGL $\geq 150 \mathrm{mg} / \mathrm{dl}, \mathrm{LDLC} \geq 100 \mathrm{mg} / \mathrm{dl}$ (Optimal) and cholesterol/ HDLC ratio $>3$ were significantly associated with hypertension. We did not find any significant association between low HDLC levels with EH. The regression model with best fit included variables age, sex, BMI and serum lipids. Increasing age, gender male, BMI and serum TGL was associated with increased risk of EH. Lowering one unit of BMI reduced the odds of hypertension by $24.2 \%$. 


\section{Conclusion}

Our findings suggest that prevalence of undetected elevated BP was high in the apparently healthy urban dwellers in NorthEastern region of India. Age, overweight, behavioural habits and dyslipidemia were major risk factors associated with $\mathrm{EH}$. All healthy adults should undergo a health check-up at regular interval for early detection and management of BP. The major contributors in causation of hypertension were modifiable risk factors, which could be controlled by lifestyle modification and medication. In addition to a healthy and active lifestyle regular measurement of BP, estimation of serum lipids and continuation of antihypertensive therapy in known hypertensives is essential for proper management and achieve control of BP and to prevent CVDs.

\section{References}

1) WHO. World Health Organization Factsheets: Hypertension. . Available from: https://www.who.int/health-topics/hypertension.

2) Beevers G, Lip GY, \&apos;brien O, E. ABC of hypertension: The pathophysiology of hypertension. British Medical Journal. 2001;322(7291):912-918. doi:10.1136/bmj.322.7291.912.

3) WHO. World Health Organisation. Non communicable diseases Factsheets. . Available from: http://www.who.int/mediacentre/factsheets.

4) Third Report of the National Cholesterol Education Program (NCEP) in Adults (Adult Treatment Panel III) final report. 4.National Cholesterol Education Program Expert Panel. Executive summary of the (NCEP) on Detection, Evaluation, and Treatment of High Blood Cholesterol in Adults (Adult Treatment Panel III). Circulation. 2002;106:3143-3421.

5) Grundy SM, Stone NJ, Bailey AL, Beam C, Birtcher KK, Blumenthal RS, et al. AHA/ACC/AACVPR/AAPA/ABC/ ACPM/ADA/AGS/APhA/ASPC/NLA/PCNA Guideline on the Management of Blood Cholesterol: A Report of the American College of Cardiology/American Heart Association Task Force on Clinical Practice Guidelines. Journal of American College of Cardiology. 2019;73(24):3168-3209. doi:10.1016/j.jacc.2018.11.002.

6) Zhang JJ, Dong X, Cao YY, Yuan YD, Yang YB, Yan YQ, et al. Clinical characteristics of 140 patients infected with SARS-CoV-2 in Wuhan. Allergy. 2020;00:1-12. doi:10.1111/all.14238.

7) Zhou F, Yu T, Du R, Fan G, Liu Y, Liu Z, et al. Clinical Course and Risk Factors for Mortality of Adult Inpatients With COVID19 in Wuhan, China: A Retrospective Cohort Study. Lancet. 2020;395(10229):30566-30569. doi:10.1016/S0140-6736(20)30566-3.

8) Fang L, Karakiulakis G, Roth M. Are patients with hypertension and diabetes mellitus at increased risk for COVID-19 infection? The Lancet Respiratory Medicine. 2020;8(4):e21-e21. doi:10.1016/s2213-2600(20)30116-8.

9) Vaduganathan M, Vardeny O, Michel T, McMurray JJV, Pfeffer MA, Solomon SD. Renin-Angiotensin-Aldosterone System Inhibitors in Patients with Covid-19. New England Journal of Medicine. 2020;382(17):1653-1659. doi:10.1056/nejmsr2005760.

10) Organisation WH. Global Health Observatory (GHO) data. . Available from: https://www.who.int/gho/ncd/risk_factors/blood_pressure_prevalence_ text.

11) Nadkar E, Y M. Epidemiology of hypertension: Indian guidelines on hypertension (I.G.H.) - III. Journal of the Association of Physicians of India. 2013;61(2):12-13. Available from: https://www.ncbi.nlm.nih.gov/pubmed/24475694.

12) Anchala R, Kannuri NK, Pant H, Khan H, Franco OH, Angelantonio D, et al. Hypertension in India: a systematic review and meta-analysis of prevalence, awareness, and control of hypertension. Journal of Hypertension. 2014;32(6):1170-1177. doi:10.1097/HJH.0000000000000146.

13) Ghosh S, Kumar M. Prevalence and associated risk factors of hypertension among persons aged 15-49 in India: a cross- sectional study. BMJ Open. 2019;9:e029714. doi:10.1136/bmjopen-2019-029714.

14) Bhansali A, Dhandania V, Deepa M. Prevalence of and risk factors for hypertension in urban and rural India: the ICMR-INDIAB study. J Human Hypertension. 2015;29:204-209. doi:10.1038/jhh.2014.57.

15) Tripathy JP, Thakur JS, Jeet G, Chawla S, Jain S. Alarmingly high prevalence of hypertension and pre-hypertension in North India-results from a large cross-sectional STEPS survey. PLoS One. 2017;12(12):e0188619. doi:10.1371/journal.pone.0188619.

16) Hazarika NC, Narain K, Biswas D, Kalita HC, Mahanta J. Hypertension In The Native Rural Population Of Assam. National Medical Journal of India. 2004;17:300-304. Available from: https://www.ncbi.nlm.nih.gov/pubmed/15736549.

17) European Society Cardiology. One in five young adults in India has high blood pressure. European Society Cardiology Press Release. 2018. Available from: https://www.escardio.org/The-ESC/Press-Office/Press-releases/One-in-five-young-adults-in-India-has-high-blood-pressure.

18) Yadav S, Boddula R, Genitta G, Bhatia V, Bansal B, Kongara S, et al. Prevalence \& risk factors of pre-hypertension \& hypertension in an affluent north Indian population. Indian Journal of Medical Research. 2008;128:712-720.

19) Vartiainen E, Pekkanen J, Koskinen S, Jousilahti P, Salomaa V, Puska P. Do changes in cardiovascular risk factors explain the increasing socioeconomic difference in mortality from ischaemic heart disease in Finland? Journal of Epidemiology \& Community Health. 1998;52(7):416-419. doi:10.1136/jech.52.7.416.

20) Goyal R, Sarwate N. A correlative study of hypertension with lipid profile. International Journal of Applied and Natural Sciences. 2014;2(2):143-150.

21) Choudhury KN, Mainuddin AK, Wahiduzzaman M, Islam SM. Serum lipid profile and its association with hypertension in Bangladesh. Vascular Health and Risk Management. 2014;10:327-327. doi:10.2147/vhrm.s61019.

22) Onwubuya EI, Anisiuba BC, Osuji CU, Ahaneku JE. Changes in Lipids and Lipoprotein Indices in Relation to the Severity of Hypertension in Newly Diagnosed Hypertensive Nigerians. ISRN Cardiology. 2012;2012:1-7. doi:10.5402/2012/972341.

23) Whelton PK, Carey RM, Aronow WS, Jr C, Collins DE, J K, et al. ACC/AHA/AAPA/ABC/ACPM/AGS/APhA/ ASH/ASPC/NMA/ PCNA Guideline for the Prevention, Detection, Evaluation, and Management of High Blood Pressure in Adults. A Report of the American College of Cardiology/American Heart Association Task Force on Clinical Practice Guideline. Hypertension. 2018;71:e13-e115. doi:10.1161/HYP.0000000000000066.

24) Bharati DR, Nandi P, Yamuna TV, Lokeshmaran A, Agarwal L, Singh JB, et al. Prevalence and Covariates of Undiagnosed Hypertension in the Adult Population of Puducherry, South India. Nepal Journal of Epidemiology. 2012;2(2):191-99. doi:10.3126/nje.v2i2.6576.

25) Shukla AN, Madan T, Thakkar BM, Parmar MM, Shah KH. Prevalence and Predictors of Undiagnosed Hypertension in an Apparently Healthy Western Indian Population. Advances in Epidemiology. 2015;2015:1-5. Available from: https://dx.doi.org/10.1155/2015/649184. doi:10.1155/2015/649184.

26) Chobanian AV, Bakris GL, Black HR, Cushman WC, Green LA, Izzo JL. The Seventh Report of the Joint National Committee on Prevention, De- 
tection, Evaluation, and Treatment of High Blood Pressure: The JNC 7 Report. Journal of the American Medical Association. 2003;289(19):2560-2571. doi:10.1001/jama.289.19.2560.

27) Gupta R. Trends in hypertension epidemiology in India. Journal of Human Hypertension. 2004;18(2):73-78. doi:10.1038/sj.jhh.1001633.

28) WHO. Salt Reduction Factsheets. . Available from: https://www.who.int/news-room/fact-sheets/detail/salt-reduction.

29) Manimunda SP, Sugunan AP, Benegal V, Balakrishna N, Rao MV, Pesala KS. Association of hypertension with risk factors \& hypertension related behaviour among the aboriginal Nicobarese tribe living in Car Nicobar Island, India. Indian Journal of Medical Research. 2011;133:287-293.

30) WHO STEPS surveillance manual: the WHO STEPwise approach to Non Communicable disease risk factor surveillance. 2017.

31) Pandey A, Patni N, Sarangi S, Singh M, Sharma K, Vellimana AK, et al. Association of exclusive smokeless tobacco consumption with hypertension in an adult male rural population of India. Tobacco Induced Diseases. 2009;5(1):1-5. doi:10.1186/1617-9625-5-15.

32) Shokeen D, Aeri BT. Risk Factors Associated with the Increasing Cardiovascular Diseases Prevalence in India: A Review. Journal of Nutrition \& Food Sciences. 2014;05(01):1-6. doi:10.4172/2155-9600.1000331. 